\title{
Changes in the expression of interleukin- $1 \beta$ and lipopolysaccharide-induced TNF factor in the oviduct of laying hens in response to artificial insemination
}

\author{
Shubash Chandra Das, Naoki Isobe and Yukinori Yoshimura \\ Graduate School of Biosphere Science, Hiroshima University, Higashi-Hiroshima 739-8528, Japan \\ Correspondence should be addressed to Y Yoshimura; Email: yyosimu@hiroshima-u.ac.jp
}

\begin{abstract}
The aim of this study was to determine the physiological significance of interleukin-1 $\beta$ (IL1B) and lipopolysaccharide-induced TNF factor (LITAF) in the fate of sperm in the oviduct of laying hens after artificial insemination (AI). Laying hens were inseminated with fresh semen, PBS or seminal plasma and tissues from different oviductal segments were collected to observe the general histology, changes in the mRNA expression of ILIB and LITAF and the localization of positive cells expressing immunoreactive IL1B (irIL1B). Semi-quantitative RT-PCR was used to observe the changes in mRNA expression of these molecules in the infundibulum, uterus, utero-vaginal junction (UVJ), and vagina after insemination. Intact sperm in the lumen and between the primary or secondary folds of the vagina were found until $6 \mathrm{~h}$ after insemination but were degraded at $12 \mathrm{~h}$. The mRNA expression of IL1B and LITAF was significantly increased in the vagina until $6 \mathrm{~h}$ after AI but remained unchanged in the other oviductal segments. In the tissue of the vagina and UVJ, irIL1B was localized in the mucosal stroma. The number of irIL1B-positive cells was increased in the vagina but almost unchanged in UVJ after insemination with semen. Significant changes were not observed in the mRNA expression and irlL1B-positive cells in the vagina after PBS or seminal plasma insemination. The increase of IL1B and LITAF in the vagina may lead to sperm degradation and elimination by cilia of surface epithelium, whereas their lower levels in UVJ may permit sperm to survive in sperm storage tubules.
\end{abstract}

Reproduction (2009) 137 527-536

\section{Introduction}

The hen oviduct consists of the infundibulum, magnum, isthmus, uterus and vagina, and the tissue between uterus and vagina which is known as utero-vaginal junction (UVJ; Johnson 2001). Following copulation or artificial insemination (AI), about $1 \%$ of the total deposited sperm are transported through the vagina to enter the sperm storage tubules (SST) of the UVJ and infundibulum, and reside there for a prolonged period. In avian species, upon copulation or insemination, the majority of deposited sperm is lost from the vagina (Bakst et al. 1994, Steele \& Wishart 1996). Such removal of sperm from the vagina is a natural process but may have biological significance in the selection of good-quality sperm, whereas survivability of sperm in the SST for a prolonged period enables female birds to produce one or more clutches of fertile eggs after a single dose of Al. The SST in UVJ is the primary site for sperm residence, and upon release from the SST, they ascend to the infundibulum where fertilization occurs (Bakst 1987, Bakst et al. 1994). In a recent study, Froman (2003) explained sperm storage in birds in terms of sperm cell behavior and concluded that the sperm residence and emergence from the SST may depend on sperm cell motility. Thus, if sperm are degraded to lose motility in the vagina and UVJ, they may not enter and survive in SST. Although a number of studies have focused on and described insights based on mechanical, histological and, to some extent, immunological aspects, a major gap still exists in our understanding of the actual physiological and molecular mechanisms that regulate the sperm removal from vagina and sperm survivability in UVJ in avian species. However, recent reports showed the increase of immunocompetent cells such as antigen presenting cells and T cells in the UVJ of low-fertility hens after $\mathrm{Al}$, suggesting that an immune response to sperm may occur in the avian oviduct (Das et al. 2005a, 2005b). Therefore, the suppression of local immunity of UVJ against sperm seems important for sperm survivability in SST.

Our recent study significantly extended relevant findings showing an increased expression of transforming growth factor- $\beta \mathrm{s}$ (TGFBS) and their receptors in UVJ during sperm storage (Das et al. 2006). Sperm also expressed TGFBs and their receptors by themselves, and their expression is correlated with sperm fertility (Das et al. 2007). Since TGFBs are immunosuppressive 
cytokines, they may function for the protection of sperm stored in the SST by suppressing anti-sperm immunoreactions (Das et al. 2006). TGFB is a potent regulatory cytokine in the immune system and its regulatory activities are modulated by the presence of varieties of inflammatory cytokines and costimulatory molecules (Li et al. 2006). This suggests that, while inducing their function, TGFBs may recruit other inflammatory cytokines in the hen oviduct in response to sperm. However, there is no information as to whether the expression of inflammatory cytokines in the hen oviduct is altered in response to sperm.

In mammals, inflammatory response by immunocompetent cells in response to sperm or semen has been suggested in the reproductive tract (Robertson et al. 1996, Rozeboom et al. 1998, 1999, Robertson 2005, 2007). There are reports that immunoregulatory TGFBs function mostly as inhibitory molecules on macrophages ( $\mathrm{Li}$ et al. 2006) and also inhibit the production of inflammatory cytokines and chemokines (Fadok et al. 1998, McDonald et al. 1999). Macrophages, however, are known as major cell types that secrete a series of cytokines, including interleukin-1 $\beta$ (IL1B) and tumor necrosis factor- $\alpha$ (TNF; Peters et al. 1986, Rautenschlein et al. 1999). If the immunoreactions are enhanced by IL1B in the oviductal mucosal tissue, it may affect the survivability of sperm. In chickens, to date, TNF has not been identified, whereas lipopolysaccharide-induced TNF factor (LITAF) that may induce the expression of TL1A (TNFSF15), a member of TNF ligand superfamily (TNF-related molecule), has been identified (Hong et al. 2006). The LITAF may also play roles in the breakdown of protein molecules and other substances because it is located in the lysosomal membrane (Moriwaki et al. 2001). Since TNF is known to exhibit cytotoxic activity to cause germ cell death in mammalian testis (Grataroli et al. 2004), molecules of the TNF ligand superfamily may also cause damage of sperm in the oviduct. The elevated expression of TGFBs in UVJ after AI (Das et al. 2006) may play a role in regulation of the expression of proinflammatory cytokines.

IL1B and TNF are the first-line co-stimulatory cytokines that mostly induce their functions to enhance immunoreactions in biological systems. Therefore, less exposure of IL1B and TNF-related molecules to sperm in the UVJ of the hen oviduct may be significant for sperm survivability. Recently, mRNA expression of IL1B, LITAF, and the TNF receptor superfamily was reported in the ovary and oviduct of laying hens, suggesting the involvement of these cytokines in the process of avian reproductive functions (Birdgham \& Johnson 2004, Subedi et al. 2007, Sundaresan et al. 2007a, 2007b). However, the physiological significance of IL1B and TNF-related molecules in the avian oviduct, particularly in relation to the voidance of sperm from the vagina, is not fully understood. It also remains unclear whether these molecules affect the sperm stored in SST in UVJ.
Thus, the goal of our present study was to examine the role of inflammatory cytokines in the fate of sperm in the hen oviduct by observing their changes in expression in different oviductal segments after insemination of the birds with fresh semen, PBS or seminal plasma. If they are enhanced in the vagina following insemination, it may be involved in the process of sperm voidance from the vagina; however, if they affect sperm they should not be increased in the tissue of UVJ. The mRNA expression of ILIB and LITAF in different oviductal segments after insemination with fresh semen or PBS or seminal plasma was investigated by RT-PCR. Histological observations of oviductal segments were made and localization of immunoreactive IL1B (irlL1B) in the vagina and UVJ was confirmed by immunohistochemistry.

\section{Results \\ Experiment 1: Histological observation}

In the vagina, the mucosal folds were developed and intact sperm were observed on the surface of mucosa for 1-6 $\mathrm{h}$ after Al (Fig. 1A and B). Degraded sperm were found at $12 \mathrm{~h}$ after $\mathrm{Al}$ (Fig. 1C), whereas no sperm and/or sperm fragments were observed in the vagina at $24 \mathrm{~h}$ after $\mathrm{Al}$ (data not shown). Head regions of the sperm at $1 \mathrm{~h}$ after Al showed smooth and long thread-like structures and the feature was kept similar until $6 \mathrm{~h}$ (Fig. 1A and B), whereas those of degraded sperm at $12 \mathrm{~h}$ after Al showed irregular surface and body structures with small and rounded particles around them (Fig. 1C). In the UVJ, SSTs were filled with sperm for 1-24 $\mathrm{h}$ after $\mathrm{Al}$ at a ratio of $\sim 50-60 \%$ (data not shown). No histological change was observed in the cells of mucosal tissues at all times after insemination examination.

\section{Experiment 2: RT-PCR analysis for IL1B and LITAF expression in oviductal segments, and TNF receptor in sperm}

PCR products of ILIB and LITAF were observed at their predicted size (138 and 229 bp respectively; Fig. 2). The expression of ILIB was not changed in the infundibulum, uterus, and UVJ during $0-24 \mathrm{~h}$ by insemination with PBS or semen (Fig. $3 \mathrm{~A}-\mathrm{C}$ ). In the vagina, insemination with semen resulted in the significant increase in $I L 1 B$ expression at 1 and $3 \mathrm{~h}$ compared with pretreatment, whereas PBS treated group did not show significant change. Significant differences between semen and PBS treatment groups were found at 1, 3, and $6 \mathrm{~h}$ after insemination (Fig. 3D). Figure 4 shows the change in expression of LITAF in the oviduct following insemination with semen or PBS. The expression of LITAF did not change in the infundibulum and UVJ from 0 to $24 \mathrm{~h}$ after insemination with semen or PBS (Fig. 4A and C). In the uterus, the expression was decreased at $12 \mathrm{~h}$ after treatment with semen or PBS, but there was no difference 
in the expression level between semen and PBS insemination groups at all times after insemination (Fig. 4B). In the vagina, a significant difference was not observed during 0-24 h within the semen or PBS insemination groups compared with pretreatment; however, the amount of expression was significantly greater in the semen insemination group than PBS group at 1 and $3 \mathrm{~h}$ of treatment (Fig. 4D). Figure 5 shows the
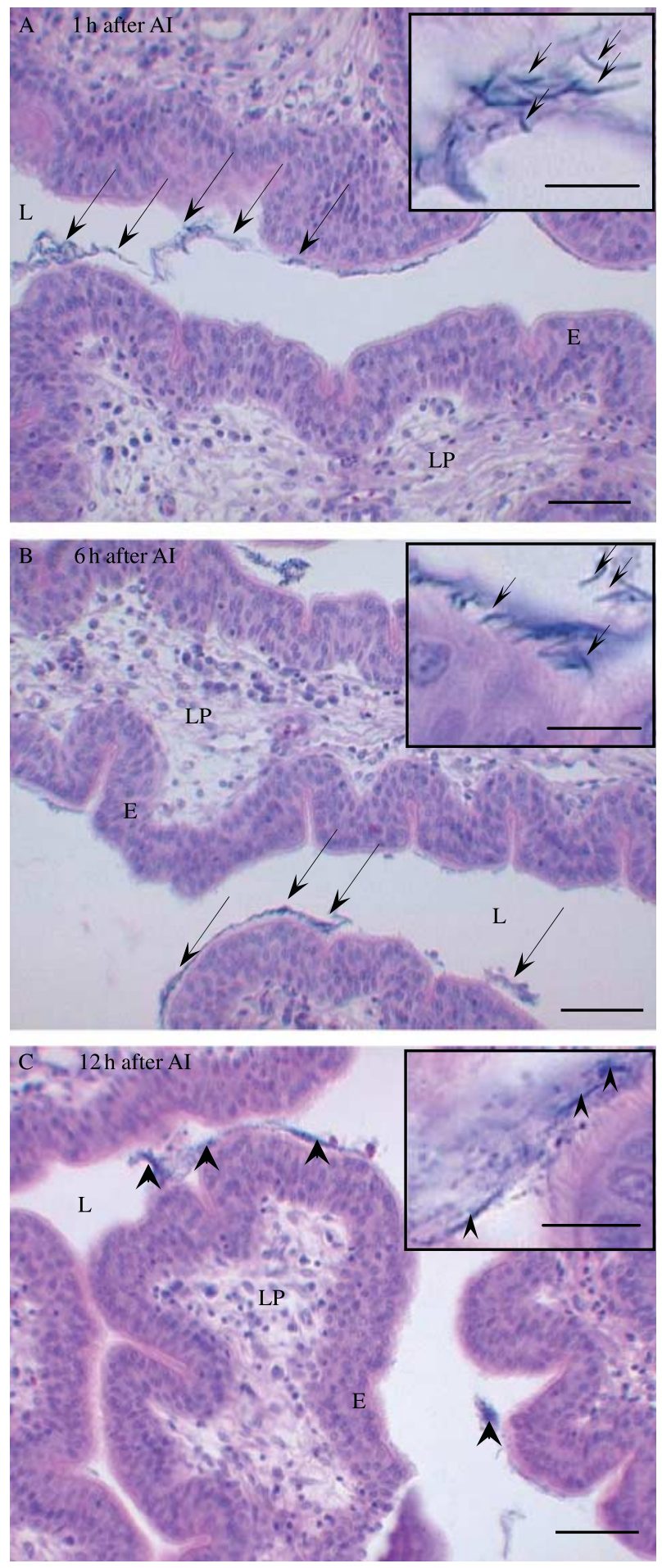

change in expression of $I L 1 B$ and LITAF during $0-3 \mathrm{~h}$ after insemination with seminal plasma in UVJ and vagina. The expression of them was not changed in both UVJ (Fig. 5A and C) and vagina (Fig. 5B and D). The mRNA expression of TNF receptor in chicken sperm was observed at the predicted product size of $440 \mathrm{bp}$ (Fig. 6).

\section{Experiment 3: Immunohistochemistry for irIL1B}

The irlL1B cells were observed in the lamina propria of the vagina (Fig. 7A and B) and UVJ (Fig. 7 C and D) before and after insemination. Numbers of irlL1B cells in the vagina were significantly increased from 1 to $6 \mathrm{~h}$ by insemination with fresh semen but were unchanged by PBS, and there were significant differences at 1, 3, and $6 \mathrm{~h}$ among semen and PBS groups (Fig. 8A). In the UVJ, however, the number of positive cells showed a significant but small increase only at $3 \mathrm{~h}$ with fresh semen, whereas in the case of PBS insemination no significant difference was observed (Fig. 8B).

\section{Discussion}

We report that ILIB and LITAF are expressed in mucosal tissue of the hen oviduct, and changed in the vagina, but not in UVJ, with Al. The significant findings of the present study are: (i) among the four oviductal segments (infundibulum, uterus, UVJ, and vagina), expression of both $I L 1 B$ and LITAF was significantly increased only in the vagina in response to semen insemination; (ii) immunopositive cells for irlL1B were observed in lamina propria and their population was significantly increased in the vagina but were almost unchanged in UVJ after semen insemination, and (iii) sperm expressed TNF receptor mRNA.

In the vagina, the expression of ILIB and LITAF was significantly increased for 1 to $6 \mathrm{~h}$ after insemination, and then returned to the level at $0 \mathrm{~h}$. The numbers of immunopositive cells for irlL1B in the stroma of the vagina were also increased during the same period of observation. Histological observation of the vagina confirmed the presence of undegraded sperm in the lumen and between the primary and secondary folds until $6 \mathrm{~h}$ after insemination but were degraded or had

Figure 1 Sections of the vagina of hen oviduct after insemination. (A) $1 \mathrm{~h}$ after insemination, (B) $6 \mathrm{~h}$ after insemination, and (C) $12 \mathrm{~h}$ after insemination $(\mathrm{Al})$. Note that intact sperm were observed in the lumen of the vagina and/or in between the primary folds of the vagina at $1 \mathrm{~h}$ and $6 \mathrm{~h}$ after insemination (arrows, A and B). Degraded parts of sperm showing irregular surface and body structures with round particles are seen in the lumen of the vagina and in between the vaginal folds at $12 \mathrm{~h}$ after $\mathrm{Al}$ (arrowheads, C). By contrast, the epithelial and stromal cells in the mucosal tissue do not show degenerative features. $E$, surface epithelium; LP, lamina propria; L, lumen. Scale bars $=50 \mu \mathrm{m}$. Insets of (A) and (B) show magnified view of the vagina with long thread-like structures of intact sperm (arrows) and (C) shows magnified view of the vagina with round particles of sperm fragments (arrowheads). Scale bars $=10 \mu \mathrm{m}$. 


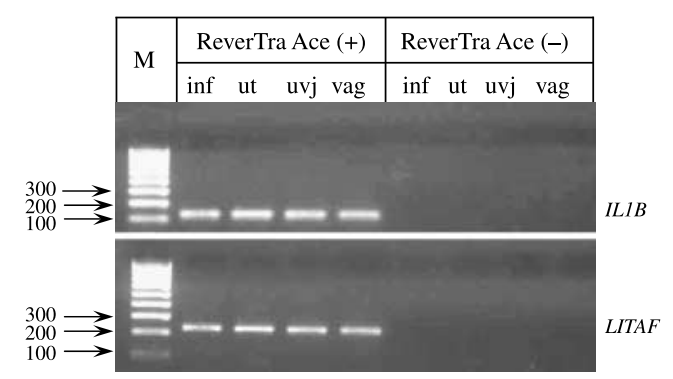

Figure 2 RT-PCR analysis of the expression of $I L 1 B$ and $L I T A F$ in tissue of the infundibulum, uterus, uterovaginal junction, and vagina. Clear bands are seen for ILIB and LITAF at $\sim 138$ and 229 bp respectively, for all oviductal segments when samples are reverse transcribed with ReverTra Ace (left). RNA samples that are subjected to reverse transcription without ReverTra Ace do not show bands either of IL1B and LITAF (right). Tissue was collected from non-inseminated laying hens at $5 \mathrm{~h}$ after oviposition. inf, infundibulum; ut, uterus; uvj, uterovaginal junction; vag, vagina; M, DNA marker of 100 bp ladder.

disappeared at 12 and $24 \mathrm{~h}$. Previous reports showed that insemination caused a dramatic influx of inflammatory cytokines into the site of semen deposition in different species (Robertson 2007). A surge of proinflammatory cytokines was observed in the stromal tissue of the endometrium within $1 \mathrm{~h}$ of insemination in mice (Sanford et al. 1992, Robertson et al. 1998) as well as in pigs (Rozeboom et al. 1998, O'Leary et al. 2004). The mRNA expression of $I L 1 B, I L 6$, and leukemia inhibitory factor were increased 2-3-fold in the endometrium after stimulation with seminal plasma (Gutsche et al. 2003). These cytokines caused influx and accumulation of a variety of inflammatory leukocytes, macrophages, dendritic cells, and granulocytes to the endometrial stroma (Bischof et al. 1994, 1995, Engelhardt et al. 1997). There are reports suggesting that avian and mammalian cytokines may perform similar tasks, although their primary structures in most cases are remarkably different (Weining et al. 1998, Staeheli et al. 2001). The higher mRNA expression of ILIB and LITAF as well as the increase of irlL1B cells in the vagina of the hen oviduct for 1-6 h after insemination with semen observed in the current study may be the eventual results of the inflammatory response to semen that may affect the fate of sperm. These results were further justified by the fact that the mucosal tissue of the vagina failed to show any increase in expression of those mRNAs or in irlL1B cells when laying hens were inseminated with the same volume of PBS. Since the vaginal tissue did not show significant changes in the expression of ILIB and LITAF within $3 \mathrm{~h}$ of seminal plasma insemination, the increase in their expression with semen might occur in response to sperm rather than seminal plasma. The expression of LITAF in the uterus was decreased after $12 \mathrm{~h}$ of semen insemination. It is assumed that this decline of LITAF expression occurred as the spontaneous changes in its expression during an ovulatory cycle because the same decline was observed in the birds inseminated with PBS.

Sperm cells in the vaginal lumen were degraded at $12 \mathrm{~h}$ after $\mathrm{Al}$, suggesting a consequence of sperm elimination from the vagina. A remarkable degree of sperm redundancy in the vagina is considered to be an important factor for the selection of good-quality sperm (Bakst et al. 1994). There are two possible factors involved in selection or loss of sperm deposited with vagina. One is the ciliary beat of vaginal epithelial cells to transport them towards the cloaca (Brillard 1993, Bakst \& Akuffo 2008). Another is the response of vaginal cells to release some molecules that may affect the sperm survivability. In addition to the basic functions, i.e. the regulation of inflammatory
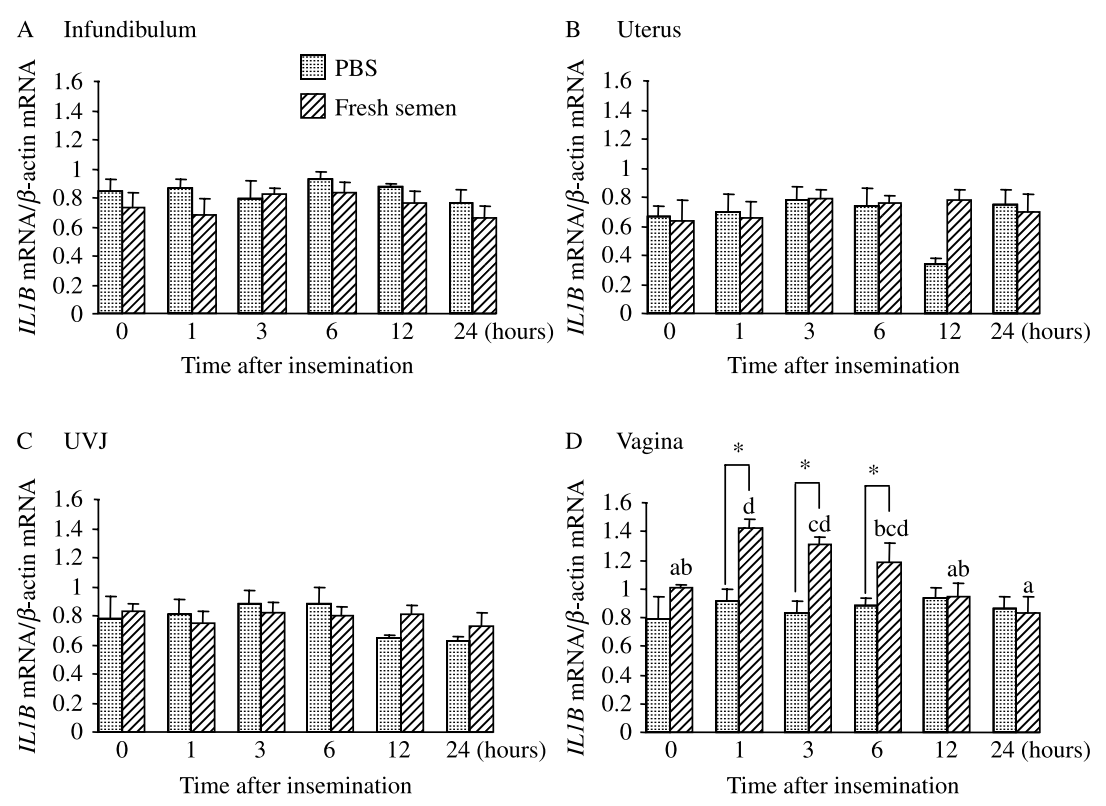

Figure 3 Changes in the expression of ILIB in the oviduct in response to insemination with semen or PBS. (A) infundibulum, (B) uterus, (C) UVJ, and (D) vagina. Each value indicates mean \pm s.E.M. $(n=4)$. Values were compared by two-way ANOVA (treatment $X$ time) followed by TukeyKraner test. In the vagina, significances were obtained in the effects of treatment $(F(1,6)$ $=6.337, P<0.05)$, time $(F(5,30)=6.597$, $P<0.001)$, and interaction $(F(5,30)=5.905$, $P<0.001)$. Values with different letters are significantly different within treatment $(P<0.05)$. *Significantly different between semen and PBS insemination within an examined time $(P<0.05)$. 

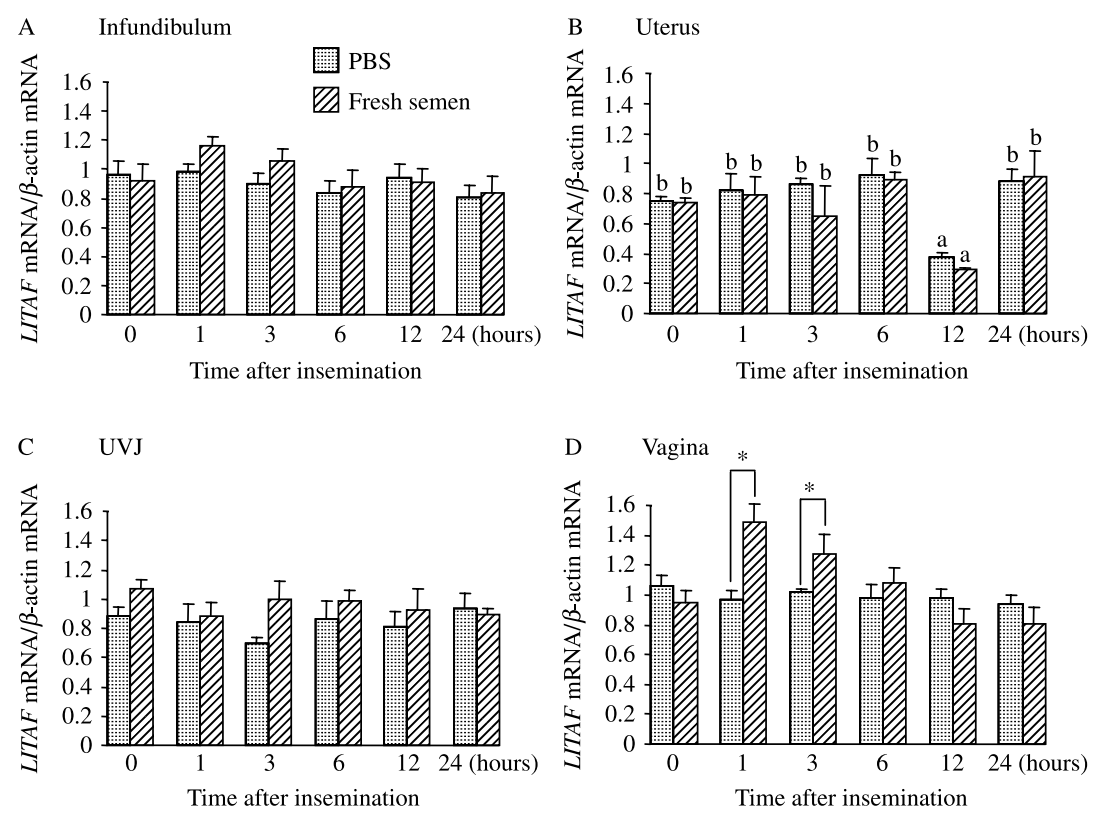

Figure 4 Changes in the expression of LITAF in the oviduct in response to insemination with semen or PBS. (A) infundibulum, (B) uterus, (C) UVJ, and (D) vagina. Each value indicates mean \pm s.E.M. $(n=4)$. Values were compared by two-way ANOVA (treatment $\mathrm{X}$ time) followed by Tukey-Kraner test. In the vagina, significances were obtained in the effects of time $(F(5,30)=3.499, P<0.05)$ and interaction $(F(5,30)=2.940, P<0.05)$. *Significantly different between semen and PBS insemination within an examined time $(P<0.05)$.

response and immunity, few subsets of the TNF superfamily, including TNF, are also known to exhibit potent cytotoxic activity by inducing apoptosis of varieties of susceptible cell lines (Nagata 1997, Gupta \& Gollapudi 2006, Chen et al. 2007). Induction of germ cell death during spermatogenesis by TNF-related apoptosis-inducing ligand was also suggested in the adult human testis (Grataroli et al. 2004). The present study showed an increase of LITAF in the vagina and confirmed the expression of TNF receptor in sperm. It has been reported that LITAF induces the expression of TNF ligand superfamily members like TNFSF15 (TL1A; Hong et al. 2006). The increased expression of LITAF in the vagina after $\mathrm{AI}$ with semen observed in the present study may cause the expression of TNF-related molecules. If such molecules are synthesized, the interaction of them with TNF receptor
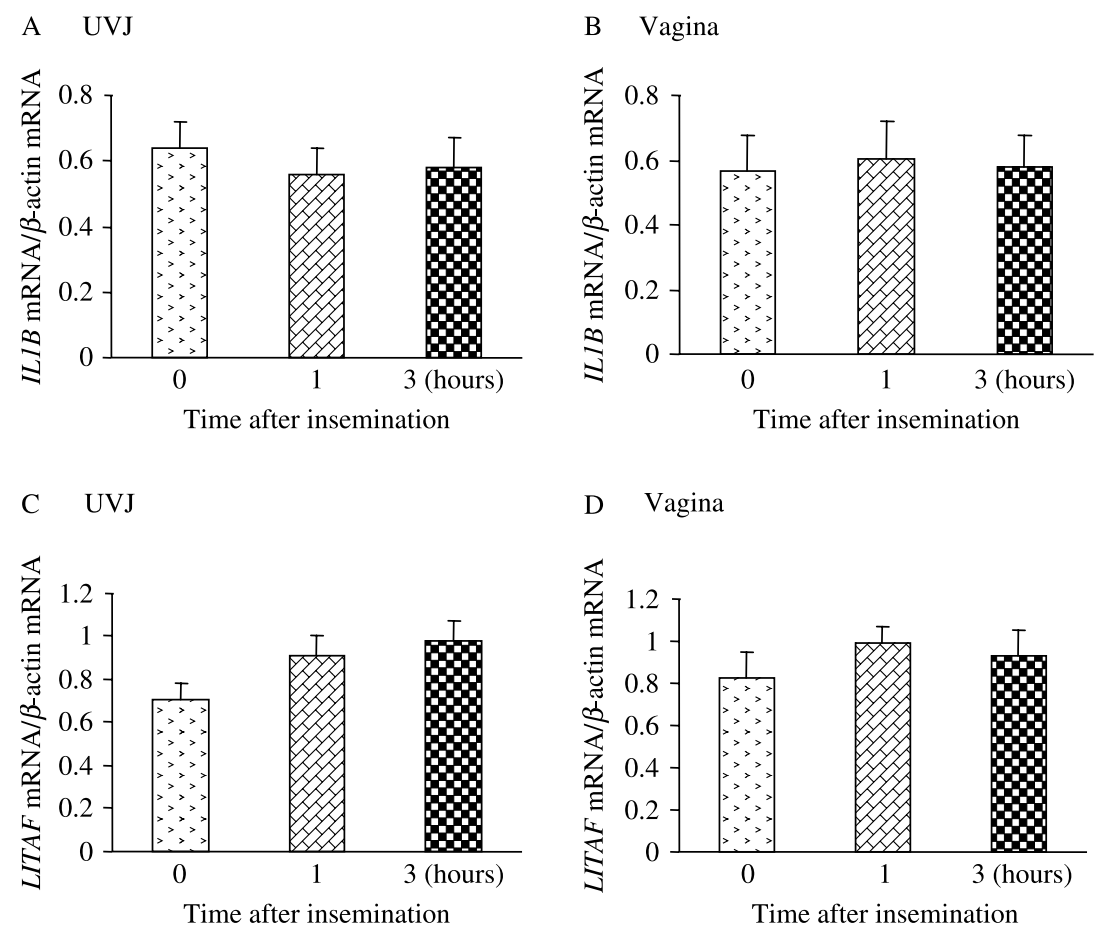

Figure 5 Effects of seminal plasma insemination on the expression of ILIB and LITAF in the uterovaginal junction and vagina. (A) and (B) $I L 1 B$ expression in the UVJ and vagina; $(C)$ and (D) LITAF expression in the UVJ and vagina; Values are mean \pm S.E.M. $(n=4)$. Data were analyzed by oneway ANOVA, followed by Tukey-Kramer test. 


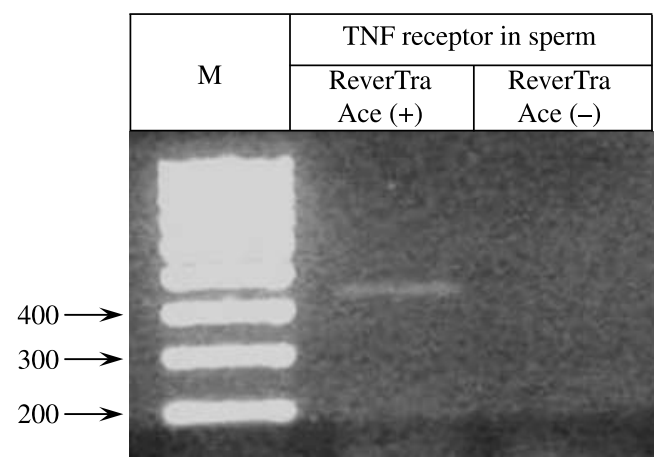

Figure 6 RT-PCR analysis of the expression of TNF receptor mRNA in sperm cells with or without ReverTra Ace. A clear band is seen for TNF receptor at $\sim 440$ bp for sperm cells when the RNA sample is reverse transcribed with ReverTra Ace (left). RNA sample subjected to reverse transcription without ReverTra Ace does not show any band for TNF receptor (right). M, DNA marker of 100 bp ladder.

in sperm may cause degradation of sperm that are unable to transverse the vaginal part of oviduct. Recent report suggested that LITAF may be located in the lysosomal membrane and play roles in the breakdown of protein molecules and other substances (Moriwaki et al. 2001). However, the significant changes in the lysosomal activity in the vaginal cells may not be induced in response to Al because those cells did not show histological changes.

Histological observation of UVJ revealed that the SST contained sperm for 1-24 h after insemination. The expression of ILIB and LITAF in UVJ was unchanged, although the populations of irlL1B cells showed only a small and short increase. These results suggest that the inflammatory response to sperm might not be enhanced in the tissue of UVJ even in the presence of abundant sperm in SST. Our previous reports revealed an increased expression of TGFBs and their receptors in UVJ, but not in the vagina after Al (Das et al. 2006). These results suggest a possible correlation between expression of IL1B, LITAF, and TGFBs in UVJ in the presence of sperm in their SST. TGFBs induce inhibitory functions on macrophages, chemokines, and proinflammatory cytokines (Peters et al. 1986, Fadok et al. 1998, McDonald et al. 1999, Rautenschlein et al. 1999, Li et al. 2006), and those produced by macrophages can act in a paracrine manner on $\mathrm{T}$ cells to suppress immune responses (Reinhold et al. 1994, 1995, Ahmad et al. 1997). There seems to be an association between the higher expression of TGFBs and lower expression of $I L 1 B$ and LITAF in the UVJ after AI. The lower levels of IL1B and LITAF in UVJ after Al suggest lower exposure of sperm to IL1B and TNF-related molecules, leading to sperm survivability in SST by protecting them from immunoreactions.

In conclusion, we have provided evidence that IL1B and LITAF mRNAs and irlL1B cells are increased in the vagina with $\mathrm{Al}$, probably in response to sperm. Mucosal tissue of UVJ that stored a sufficient number of sperm, however, does not show their increased expression. The increase of IL1B and TNF-related molecules in the vagina may lead to sperm degradation and elimination by cilia of surface epithelium, whereas their lower levels in UVJ may permit sperm to survive in SST.

\section{Materials and Methods}

\section{Birds, treatment, and tissue collection}

Healthy single-comb White Leghorn laying hens, 32 weeks of age and laying 5 or more eggs at regular intervals were maintained in individual cages under a photoperiod of $14 \mathrm{~h}$
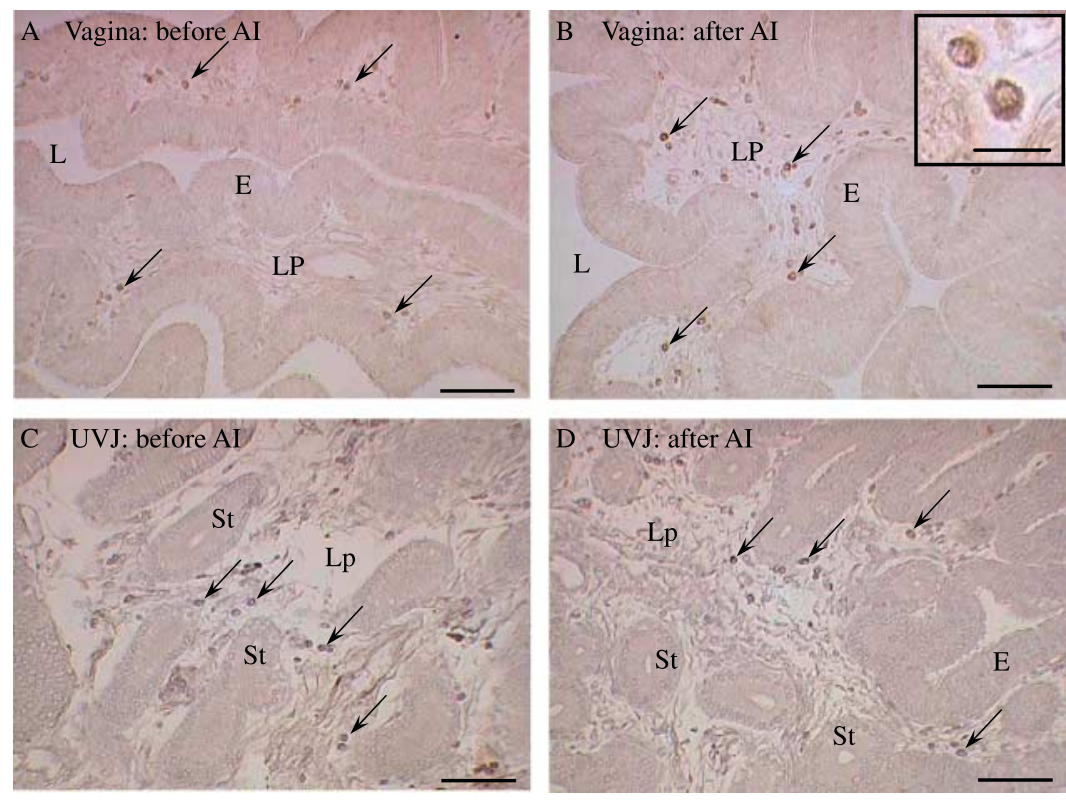

Figure 7 Sections of vagina and uterovaginal junction of non-inseminated and inseminated birds immunostained for irlL1B. (A) Vagina before insemination, (B) Vagina $1 \mathrm{~h}$ after insemination, (C) UVJ before insemination, and (D) UVJ $1 \mathrm{~h}$ after insemination. Arrows indicate positive cells for irIL1B in the mucosal tissues of vagina and UVJ. E, surface epithelium; LP, lamina propria; L, lumen, St, sperm storage tubule. Scale bar $=50 \mu \mathrm{m}$. Inset of (B) shows magnified view of positive cells for irlL1B. Scale bar $=25 \mu \mathrm{m}$. 


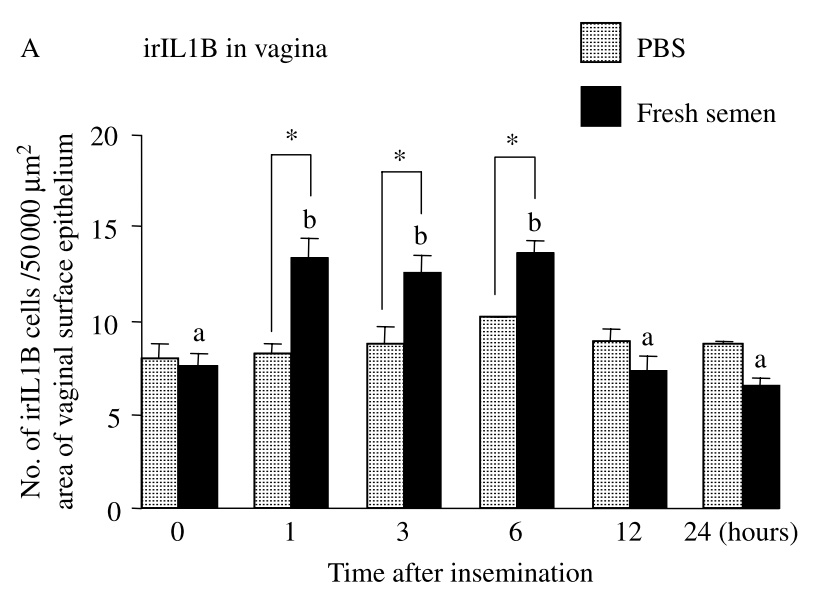

B irIL1B in UVJ

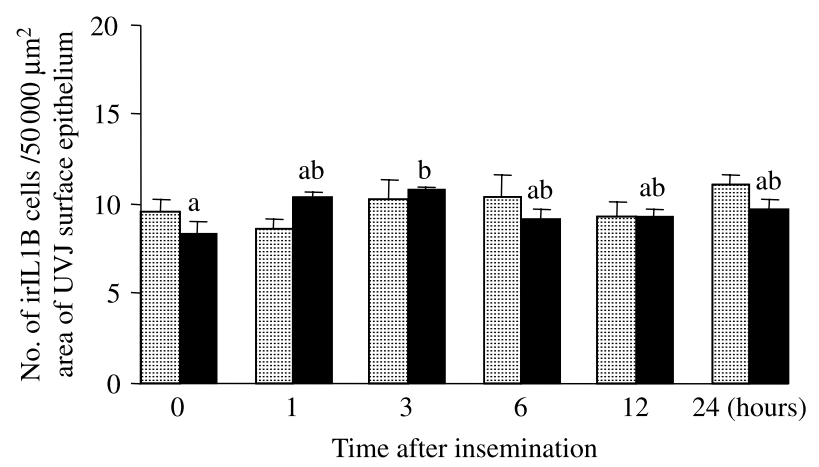

Figure 8 Frequency of the populations of positive cells for irlL1B in the oviduct inseminated with semen or PBS. (A) irlL1B in the vaginal stroma, (B) irlL1B in the UVJ stroma. Each value indicates mean \pm s.E.M. $(n=4)$. Values were compared by two-way ANOVA (treatment X time) followed by Tukey-Kraner test. In the vagina, significances for irlL1B were obtained in the effects of treatment $(F(1,6)=16.986, P<0.05)$, time $(F(5,30)=14.981, P<0.001)$ and interaction $(F(5,30)=9.905$, $P<0.001)$. Values with different letters are significantly different within treatment $(P<0.05)$. *Significantly different between semen and PBS insemination within an examined time $(P<0.05)$.

light:10 h darkness and provided with free access to food and water. The hens were intravaginally inseminated with $\sim 0.05 \mathrm{ml}$ fresh semen containing $\sim 2 \times 10^{8}$ sperm or PBS (control; Nissui Pharmaceutical Co., Ltd, Tokyo, Japan) from the cloaca using a $1 \mathrm{ml}$ plastic syringe. To examine whether the seminal plasma components were involved in the effects of semen insemination on cytokine expression, seminal plasma $(0.05 \mathrm{ml})$ was also used for insemination. Semen was collected by abdominal massage from White Leghorn roosters $(n=4)$ maintained under similar conditions to the laying hens. Seminal plasma was separated from the fresh semen by centrifuging at $1700 \mathrm{~g}$ for $10 \mathrm{~min}$.

The mucosal tissues of infundibulum (tubular region), uterus, UVJ, and vagina were collected for observation of the expression of ILIB and LITAF at $0,1,3,6,12$, and $24 \mathrm{~h}$ after insemination with fresh semen or PBS ( $n=4$ each). The tissue was collected at $5 \mathrm{~h}$ after oviposition (the time of Al was 5, 4, and $2 \mathrm{~h}$ after oviposition for the groups of 0,1 , and $3 \mathrm{~h}$ after $\mathrm{Al}$, and was 1 and $19 \mathrm{~h}$ before oviposition for the groups of 6 and $24 \mathrm{~h}$ after $\mathrm{Al}$ ), except for the group of $12 \mathrm{~h}$ after insemination in which the tissue was collected just prior to oviposition. The time of oviposition was estimated based on the observations of the oviposition times for several weeks and the exact time of oviposition on the day of tissue collection. Since the significant effects of semen insemination on the expression of $I L 1 B$ and LITAF was observed within $3 \mathrm{~h}$ of insemination, the tissues from four oviductal segments were collected at 0,1 , and $3 \mathrm{~h}$ after insemination with seminal plasma $(n=4$ each). When oviductal tissues were collected, the birds were killed under anesthesia with Nembutal (Abbott Laboratories). Birds were handled in accordance with regulations approved by the Animal Experiment Committee of Hiroshima University, Japan.

\section{Experiment 1: Histological observation}

Tissues from the vagina and UVJ of all birds were fixed with Bouin's solution followed by embedding in paraffin in the usual manner. Paraffin sections ( $4 \mu \mathrm{m}$ in thickness) were air-dried on silane-coated slides. After deparaffinization, sections were stained with hematoxylin and eosin to observe the general structure of the mucosal tissues and sperm distribution in the oviductal lumen.

\section{Experiment 2: RT-PCR analysis for the expression of IL1B, LITAF, and TNF receptor}

\section{Extraction of total RNA}

For total RNA extraction from oviductal segments, mucosal tissues from the infundibulum (tubular region), uterus, UVJ, and vagina were collected and added to $1 \mathrm{ml}$ Sepasol RNA I Super (Nacalai Tesque Inc., Kyoto, Japan). Extraction was performed as described previously by Barua \& Yoshimura (2004). Observation was also made for the possible expression of TNF receptor mRNA in chicken sperm. Collection of semen samples and RNA isolation were performed as described in our previous studies (Das et al. 2006, 2007). The pellet of RNA was suspended in TE buffer and incubated with DNase 1 (Roche Diagnostics $\mathrm{GmbH}$ ) at a concentration of $10 \mathrm{U} / \mu \mathrm{l}$. RNA concentration was measured with Gene Quant Pro (Amersham Pharmacia Biotech.) and stored at $-80{ }^{\circ} \mathrm{C}$ until further analysis.

\section{Semi-quantitative RT-PCR}

Semi-quantitative RT-PCR was performed as described previously by Das et al. (2006). RNA samples were reverse transcribed at $42{ }^{\circ} \mathrm{C}$ for $30 \mathrm{~min}$ followed by heat inactivation at $99{ }^{\circ} \mathrm{C}$ for $10 \mathrm{~min}$ using a Programmable Thermal Controller PTC-100 (MJ Research Inc., Waltham, MA, USA). For transcription, $10 \mu \mathrm{l}$ reaction mixture was prepared containing $1 \mu \mathrm{g}$ total RNA, $1 \times$ RT buffer, $1 \mathrm{mM}$ each dNTP mixture, $20 \mathrm{U}$ RNase inhibitor, $0.5 \mathrm{mM}$ oligo (dT), and $50 \mathrm{U}$ ReverTra Ace (Toyobo Co. Ltd, Osaka, Japan). Some of the samples were treated with the same process but without ReverTra Ace that was used to confirm the absence of genomic DNA in PCR samples. Primer information for IL 1B (accession no: NM_204524), LITAF 
Table 1 List of primers with references/accession numbers.

\begin{tabular}{|c|c|c|c|}
\hline Primers & Observed (bp) & Sequences & References/accession number \\
\hline IL $1 B$ & 138 & F: $5^{\prime}$-GGGCATCAAGGGCTACAA-3' $3^{\prime}$ & Subedi et al. (2007) \\
\hline LITAF & 229 & $\begin{array}{l}\text { R: 5'-CTGTCCAGGCGGTAGAAGAT-3' } \\
\text { F: 5'-TGTGTATGTGCAGCAACCCGTAGT-3' } \\
\text { R: 5'-GGCATTGCAATTTGGACAGAAGT-3' }\end{array}$ & $\begin{array}{l}\text { NM_204524 } \\
\text { Hong et al. (2006) } \\
\text { AY765397 }\end{array}$ \\
\hline TNF receptor & 440 & $\begin{array}{l}\text { F: 5'-CACAGAATGTAAGCCCTGTCC-3' } \\
\text { R: } 5^{\prime} \text {-TGGAGTTCTGCGATCCTGCATT-3' }\end{array}$ & $\begin{array}{l}\text { Abdalla et al. (2004) } \\
\text { BAC55966 }\end{array}$ \\
\hline$\beta$-actin & & $\begin{array}{l}\text { F: 5'-TTCCAGCCATCTTTCTTG-3' } \\
\text { R: 5'-TCCTTCTGCATCCTGTCA-3' }\end{array}$ & $\begin{array}{l}\text { Kost et al. (1983) } \\
\text { X00182 }\end{array}$ \\
\hline
\end{tabular}

(Hong et al. 2006, accession no: AY765397), TNF receptor (Abdalla et al. 2004, accession no: BAC55966), and chicken $\beta$-actin (Kost et al. 1983, accession no: X00182) are shown in Table 1. A mixture of $25 \mu \mathrm{l}$ volume consisting of $0.2 \mu \mathrm{M}$ specific primers, a $0.5 \mu \mathrm{l}$ aliquot of cDNA, $1 \times$ PCR buffer, $0.2 \mathrm{mM}$ dNTP mixture, $0.626 \cup$ TaKaRa Taq (TaKaRa Bio Inc., Shiga, Japan), and $19 \mu \mathrm{l}$ DNase-free water was subjected to semi-quantitative PCR to observe mRNA expression. The protocol for the PCR amplification was as follows: denaturation at $95{ }^{\circ} \mathrm{C}$ for $1 \mathrm{~min} ; 35,30$ or 40 cycles of denaturation for IL $1 B$, LITAF, and TNF receptor respectively at $95{ }^{\circ} \mathrm{C}$ for $1 \mathrm{~min}$; annealing at $62{ }^{\circ} \mathrm{C}$ (for $I L 1 B$ and TNF receptor) or $68^{\circ} \mathrm{C}$ (for LITAF) for $1 \mathrm{~min}$; extension at $72{ }^{\circ} \mathrm{C}$ for $2 \mathrm{~min}$ and final extension at $72{ }^{\circ} \mathrm{C}$ for $10 \mathrm{~min}$ in a programmable thermal controller PTC-100 (MJ Research Inc.). Chicken $\beta$-actin was used as an internal control. PCR amplification for $\beta$-actin CDNA was performed as follows: denaturation at $95^{\circ} \mathrm{C}$ for $1 \mathrm{~min} ; 30$ cycles of denaturation at $95^{\circ} \mathrm{C}$ for $1 \mathrm{~min}$; annealing at $58{ }^{\circ} \mathrm{C}$ for $1 \mathrm{~min}$; extension at $72{ }^{\circ} \mathrm{C}$ for $2 \mathrm{~min}$ and final extension at $72{ }^{\circ} \mathrm{C}$ for $10 \mathrm{~min}$. In preliminary experiments, different numbers of cycles $(25,30,35$, and 40 cycles) for IL $1 B$ and LITAF were tested in various samples from the vagina to optimize amplification. PCR products were electrophoresed in a $2 \%(\mathrm{w} / \mathrm{v})$ agarose gel with $0.4 \%$ ethidium bromide. Band density for ILIB and LITAF was quantified with reference to that of $\beta$-actin using UN-SCAN-IT gel (version 6.1, Silk Scientific Corporation, Orem, UT, USA) and the ratios of either $I L 1 B$ or LITAF to $\beta$-actin were obtained.

\section{Experiment 3: Immunohistochemistry for irIL1B}

The sections prepared as described in Experiment 1 were used for immunostaining to confirm the localizations of irlL1B in tissues of the vagina and UVJ. For irlL1B immunostaining, sections were incubated with $20 \mu \mathrm{g} / \mathrm{ml}$ proteinase $\mathrm{K}$ (SigmaAldrich) for $25 \mathrm{~min}$ at $37^{\circ} \mathrm{C}$. After washing in PBS for $15 \mathrm{~min}$ ( $5 \mathrm{~min} \times 3$ times), sections were incubated with $1.5 \mu \mathrm{l} / \mathrm{ml}$ normal goat serum (Vector Laboratories, Inc., Burlingame, CA, USA) for $1 \mathrm{~h}$. They were then incubated with rabbit polyclonal antibody to chicken IL1B antibody (Abcam Ltd, Cambridge, UK) diluted to 1:100 in PBS containing 0.05\% BSA (Nacalai Tesque Inc.). All sections were incubated overnight at $4{ }^{\circ} \mathrm{C}$. After washing with PBS ( 5 min $\times 3$ times), sections were incubated with biotinylated anti-rabbit IgG (Vector Laboratories, Inc.) for $2 \mathrm{~h}$ and with avidin peroxidase complex (Nichirei Corporation, Tokyo, Japan) for $30 \mathrm{~min}$. Sections were washed again in PBS (5 min $\times 3$ times) and immunoprecipitates were visualized by incubating with $0.02 \%(\mathrm{w} / \mathrm{v})$ $3^{\prime}, 3^{\prime}$-diaminobenzidine tetrahydrochloride (Nacalai Tesque Inc.) and $0.001 \%(\mathrm{v} / \mathrm{v}) \mathrm{H}_{2} \mathrm{O}_{2}$ in $0.05 \mathrm{M}$ Tris- $\mathrm{HCl}$ buffer $(\mathrm{pH}$ 7.6). Slides were counterstained with hematoxylin, dehydrated, and covered. Control slides were prepared as the same manner except that the first antibody was replaced with normal rabbit IgG.

\section{Image analysis}

The populations of SST-containing sperm and immunopositive cells for irlL1B in the stroma of the vagina and UVJ were observed and analyzed under a light microscope with a computer-assisted image analysis system (Image-Pro Plus; Media Cybernetics, Silver Spring, MD, USA). Immunopositive cells were counted in five different regions $\left(\sim 7-10 \times 10^{4} \mu \mathrm{m}^{2}\right.$ area in each count) randomly selected from 3 to 4 slides of each vagina or UVJ section. The number of cells positive for irIL1B in a $5 \times 10^{4} \mu \mathrm{m}^{2}$ area was then calculated.

\section{Statistical analysis}

Differences in $I L 1 B$ or LITAF expression and in the number of immunopositive cells for irlL1B among treatment groups (insemination with PBS or fresh semen at 0, 1, 3, 6, 12, and $24 \mathrm{~h}$ ) were analyzed by repeated measure two-way ANOVA using StatView, version 5, SAS institute, Cary, USA. Data on IL1B or LITAF expression after seminal plasma insemination were analyzed by one-way ANOVA. Significance of differences between PBS and fresh-semen groups among each time of insemination within each treatment was analyzed using Tukey-Kramer test. Differences were considered significant when $P<0.05$.

\section{Declaration of interest}

The authors declare that there is no conflict of interest that would prejudice the impartiality of this scientific work.

\section{Funding}

This work was supported by a Grant-in-Aid for scientific research from the Japanese Society for the Promotion of Science (JSPS). 


\section{Acknowledgements}

We would like to thank Dr Takashi Bungo, Graduate School of Biosphere Science, Hiroshima University, Japan for help with statistical analyses.

\section{References}

Abdalla SA, Horiuchi H, Furusawa S \& Matsuda H 2004 Molecular study on chicken tumor necrosis factor receptor-II and tumor necrosis factor receptor-associated factor-5. Veterinary Immunology and Immunopathology 98 31-41.

Ahmad S, Choudhry MA, Shankar R \& Sayeed MM 1997 Transforming growth factor- $\beta$ negatively modulates T-cell responses in sepsis. FEBS Letters $402213-218$

Bakst MR 1987 Quantification of intraepithelial lymphocytes in the turkey utero-vaginal junction. Poultry Science 66 2036-2038.

Bakst MR \& Akuffo V 2008 Serotonin localization in the turkey vaginal but not sperm storage tubule epithelia. Poultry Science 87 356-361.

Bakst MR, Wishart G \& Brillard JP 1994 Oviductal sperm selection, transport, and storage in poultry. Poultry Science Reviews 5 117-143.

Barua A \& Yoshimura Y 2004 Changes in the expression of major histocompatability complex class II mRNA in response to inoculation with Salmonella enteritidis in cultured hen ovarian tissue. Journal of Poultry Science 41 281-288.

Birdgham JT \& Johnson AL 2004 Alternatively spliced variants of Gallus gallus TNFRSF23 are expressed in the ovary and differentially regulated by cell signaling pathways. Biology of Reproduction 70 972-979.

Bischof RJ, Brandon MR \& Lee CS 1994 Studies on the distribution of immune cells in the uteri of prepubertal and cycling gilts. Journal of Reproductive Immunology 26 111-129.

Bischof RJ, Brandon MR \& Lee CS 1995 Cellular immune responses in the pig uterus during pregnancy. Journal of Reproductive Immunology 29 161-178.

Brillard JP 1993 Sperm storage and transport following natural mating and artificial insemination. Poultry Science 72 923-928.

Chen CC, Young JL, Monzon RI, Chen N, Todorovic V \& Lau LF 2007 Cytotoxicity of TNF- $\alpha$ is regulated by integrin-mediated matrix signaling. EMBO Journal 26 1257-1267.

Das SC, Nagasaka N \& Yoshimura Y 2005a Effects of repeated artificial insemination on the structure and function of oviductal sperm storage tubules in hens. Journal of Poultry Science 42 39-47.

Das SC, Nagasaka N \& Yoshimura Y 2005b Changes in the localization of antigen presenting cells and $\mathrm{T}$ cells in the utero-vaginal junction after repeated artificial insemination in laying hens. Journal of Reproduction and Development 51 683-687.

Das SC, Isobe N, Nishibori M \& Yoshimura Y 2006 Expression of transforming growth factor- $\beta$ isoforms and their receptors in uterovaginal junction of hen oviduct in presence or absence of resident sperm with reference to sperm storage. Reproduction 132 781-790.

Das SC, Isobe N \& Yoshimura Y 2007 Changes in the mRNA expression of sperm transforming growth factor $\beta$-isoforms and their receptors with reference to fertility during in vitro storage of fowl semen. Journal of Poultry Science 44 189-197.

Engelhardt H, Croy BA \& King GJ 1997 Role of uterine immune cells in early pregnancy in pigs. Journal of Reproduction and Fertility $\mathbf{5 2}$ $115-131$

Fadok VA, Bratton DL, Konowal A, Freed PW, Westcott JY \& Henson PM 1998 Macrophages that have ingested apoptotic cells in vitro inhibit proinflammatory cytokine production through autocrine/paracrine mechanisms involving TGF- $\beta$, PGE2, and PAF. Journal of Clinical Investigation 101 890-898.

Froman DP 2003 Deduction of a model for sperm storage in the oviduct of the domestic fowl (Gallus domesticus). Biology of Reproduction 69 248-253.

Grataroli R, Vindrieux D, Selva J, Felsenheld C, Ruffion A, Decaussin M \& Benahmed M 2004 Characterization of tumour necrosis factor- $\alpha$-related apoptosis-inducing ligand and its receptors in the adult human testis. Molecular Human Reproduction 10 123-128.
Gupta S \& Gollapudi S 2006 TNF- $\alpha$-induced apoptosis in human naïve and memory $\mathrm{CD}+\mathrm{T}$ cells in aged humans. Experimental Gerontology 41 $69-77$.

Gutsche S, von Wolff M, Strowitzki T \& Thaler CJ 2003 Seminal plasma induces mRNA expression of IL-1 $\beta$, IL- 6 and LIF in endometrial epithelial cells in vitro. Molecular Human Reproduction 9 785-791.

Hong YH, Lillehoj HS, Lee SH, Park DW \& Lillehoj EP 2006 Molecular cloning and characterization of chicken lipopolysaccharide-induced TNF- $\alpha$ factor (LITAF). Developmental and Comparative Immunology 30 919-929.

Johnson AL 2001 Reproduction in the female. In Sturkie's Avian Physiology, 5 edn, pp 569-596. Ed. GC Whittow. San Diego: Academic Press.

Kost TA, Theodorakis N \& Hughes SH 1983 The nucleotide sequence of the chick cytoplasmic $\beta$-actin gene. Nucleic Acids Research 11 8287-8301.

Li MO, Wan YY, Sanjabi S, Robertson AK \& Flavell RA 2006 Transforming growth factor- $\beta$ regulation of immune responses. Annual Review of Immunology 24 99-146.

McDonald PP, Fadok VA, Bratton D \& Henson PM 1999 Transcriptional and translational regulation of inflammatory mediator production by endogenous TGF- $\beta$ in macrophages that have ingested apoptotic cells. Journal of Immunology 163 6164-6172.

Moriwaki Y, Begum NA, Kobayashi M, Matsumoto M, Toyoshima K \& Seya T 2001 Mycobacterium bovis Bacillus Calmette-Guerin and its cell wall complex induce a novel lysosomal membrane protein, SIMPLE, that bridges the missing link between lipopolysaccharide and p53-inducible gene, LITAF (PIG7), and estrogen-inducible gene, EET-1. Journal of Biological Chemistry 276 23065-23076.

Nagata S 1997 Apoptosis by death factor. Cell 88 355-365.

O'Leary S, Jasper MJ, Warnes GM, Armstrong DT \& Robertson SA 2004 Seminal plasma regulates endometrial cytokine expression, leukocyte recruitment and embryo development in the pig. Reproduction 128 237-247.

Peters PM, Ortaldo JR, Shalaby MR, Svedersky LP, Nedwin GE, Bringman TS, Hass PE, Aggarwal BB, Herberman RB, Goeddel DV et al. 1986 Natural killer-sensitive targets stimulate production of TNF- $\alpha$ but not TNF- $\beta$ (lymphotoxin) by highly purified human peripheral blood large granular lymphocytes. Journal of Immunology 137 2592-2598.

Rautenschlein S, Subramanian A \& Sharma JM 1999 Bioactivities of a tumour necrosis-like factor released by chicken macrophages. Developmental and Comparative Immunology 23 629-640.

Reinhold D, Bank U, Buhling F, Lendeckel U, Ulmer AJ, Flad HD \& Ansorge S 1994 Transforming growth factor- $\beta 1$ (TGF- $\beta 1$ ) inhibits DNA synthesis of PWM-stimulated PBMC via suppression of IL-2 and IL-6 production. Cytokine 6 382-388.

Reinhold D, Bank U, Buhling F, Lendeckel U \& Ansorge S 1995 Transforming growth factor- $\beta 1$ inhibits interleukin-10 mRNA expression and production in pokeweed mitogen-stimulated peripheral blood mononuclear cells and T cells. Journal of Interferon \& Cytokine Research 15 685-690.

Robertson SA 2005 Seminal plasma and male factor signalling in the female reproductive tract. Cell and Tissue Research 322 43-52.

Robertson SA 2007 Seminal fluid signaling in the female reproductive tract: lessons from rodents and pigs. Journal of Animal Science 85 36-44.

Robertson SA, Mau VJ, Tremellen KP \& Seamark RF 1996 Role of high molecular weight seminal vesicle proteins in eliciting the uterine inflammatory response to semen in mice. Journal of Reproduction and Fertility 107 265-277.

Robertson SA, Allanson M \& Mau VJ 1998 Molecular regulation of uterine leukocyte recruitment during early pregnancy in the mouse. Trophoblast Research 11 101-119.

Rozeboom KJ, Troedsson MHT \& Crabo BG 1998 Characterization of uterine leukocyte infiltration in gilts after artificial insemination. Journal of Reproduction and Fertility 114 195-199.

Rozeboom KJ, Troedsson MH, Molitor TW \& Crabo BG 1999 The effect of spermatozoa and seminal plasma on leukocyte migration into the uterus of gilts. Journal of Animal Science 77 2201-2206.

Sanford TR, De M \& Wood GW 1992 Expression of colony-stimulating factors and inflammatory cytokines in the uterus of CD1 mice during days 1 to 3 of pregnancy. Journal of Reproduction and Fertility 94 213-220.

Staeheli P, Puehler F, Schneider K, Göbel TW \& Kaspers B 2001 Cytokines of birds: conserved functions - a largely different look. Journal of Interferon \& Cytokine Research $21993-1010$. 
Steele MG \& Wishart GJ 1996 Demonstration that the removal of sialic acid from the surface of chicken spermatozoa impedes their transvaginal migration. Theriogenology 46 1037-1044.

Subedi K, Isobe N, Nishibori M \& Yoshimura Y 2007 Changes in the expression of Toll-like receptor mRNAs during follicular growth and in response to lipopolysaccharide in the ovarian follicles of laying hens. Journal of Reproduction and Development 53 1227-1235.

Sundaresan NR, Anish D, Sastry KVH, Saxena VK, Mohan J \& Ahmed KA 2007a Cytokines in reproductive remodeling of molting White Leghorn hens. Journal of Reproductive Immunology 73 39-50.

Sundaresan NR, Anish D, Sastry KVH, Saxena VK, Mohan J \& Saxena M $2007 b$ Differential expression of lipopolysaccharide-induced TNF- $\alpha$ factor (LITAF) in reproductive tissues during induced molting of White Leghorn hens. Animal Reproduction Science 102 335-342.
Weining KC, Sick C, Kaspers B \& Staeheli P 1998 A chicken homolog of mammalian interleukin-1 $\beta$ : cDNA cloning and purification of active recombinant protein. European Journal of Biochemistry 258 994-1000.

Received 23 April 2008

First decision 28 May 2008

Revised manuscript received 20 November 2008

Accepted 9 December 2008 